\title{
The Current Portrayal of Non-Variceal Upper Gastrointestinal Bleeding in a Portuguese Tertiary Center
}

\author{
Daniela Falcão Joana Alves da Silva Tiago Pereira Guedes Mónica Garrido \\ Inês Novo Isabel Pedroto \\ Gastroenterology Department, Centro Hospitalar Universitário do Porto, Porto, Portugal
}

\section{Keywords}

Endoscopic hemostasis · Gastrointestinal hemorrhage . Hematemesis · Peptic ulcer hemorrhage · Upper gastrointestinal tract

\section{Abstract}

Introduction: Non-variceal upper gastrointestinal bleeding (NVUGIB) is an important healthcare problem whose epidemiology and outcomes have been changing throughout the years. The main goal of this study was to characterize the current demographics, etiologies, and risk factors of NVUGIB. Methods: Analysis of clinical, endoscopic, and outcome data from patients who were admitted for NVUGIB between January 2016 and January 2019 in an emergency department of a tertiary hospital center. Results: A total of 522 patients were included, with a median age of 71 years, mainly men, with multiple comorbidities. Most patients were directly admitted, while the others were transferred from other hospitals. Peptic ulcer disease was the most common cause of NVUGIB and it was followed by tumor bleeding. Esophagogastroduodenoscopy was performed within $<12 \mathrm{~h}$ after hospital admission in $51.9 \%$. In-hospital rebleeding occurred in $6.9 \%$ and overall mortality was $4.2 \%$. Transferred patients had superior Glasgow-Blatchford score (GBS), required more blood transfusion, endoscopic and surgical interventions, and presented higher rebleeding rate, with similar mortality. Complete Rockall score (CRS) and GBS were predictors of endoscopic therapy. Surgery need was only related to CRS. Patients who rebled had superior pre-endoscopic Rockall score (RS), CRS, and GBS. Mortality was increased in patients with higher RS and CRS. Discussion/Conclusion: Ageing and increasing comorbidities have not been related to worse outcomes in NVUGIB. These findings seem to be the consequence of the correct use of both diagnostic and therapeutic tools in an organized and widely accessible healthcare system.

(c) 2021 Sociedade Portuguesa de Gastrenterologia Published by S. Karger AG, Basel

\section{O Retrato Atual Da Hemorragia Digestiva Alta Não- Hipertensiva Num Centro Terciário Português}

\section{Palavras Chave}

Hemostase endoscópica · Hemorragia gastrointestinal · Hematemeses · Hemorragia ulcerosa péptica · Trato gastrointestinal superior karger@karger.com www.karger.com/pjg

Karger $\stackrel{\text { ' }}{5}$

BOPEN ACCESS (c) 2021 Sociedade Portuguesa de Gastrenterologia. Published by S. Karger AG, Basel

This article is licensed under the Creative Commons AttributionNonCommercial-NoDerivatives 4.0 International License (CC BYNC-ND) (http://www.karger.com/Services/OpenAccessLicense). Usage and distribution for commercial purposes as well as any distribution of modified material requires written permission.
Correspondence to:

Daniela Falcão, danielateixeirafalcao@gmail.com 


\section{Resumo}

Introdução: Hemorragia digestiva alta não-hipertensiva (HDANH) é um problema de saúde cuja epidemiologia e prognóstico têm-se alterado ao longo dos anos. O principal objetivo deste trabalho foi analisar a caracterização demográfica, etiologias e fatores de risco para HDANH. Métodos: Análise de dados clínicos, endoscópicos e prognóstico de doentes admitidos por HDANH entre janeiro/2016 e janeiro/2019 no serviço de urgência de um hospital terciário. Resultados: Foram incluídos 522 doentes, idade mediana de 71 anos, maioritariamente homens, com múltiplas comorbilidades. A maioria foi admitida diretamente, os restantes foram transferidos de outros hospitais. A doença-ulcerosa-péptica foi a causa mais frequente de HDANH, seguida pela etiologia neoplásica. Esofagogastroduodenoscopia foi realizada em menos de 12horas após admissão em 51.9\%. Recidiva hemorrágica ocorreu em $6.9 \%$ e a taxa global de mortalidade foi $4.2 \%$. Os doentes transferidos registaram um score GlasgowBlatchford (GBS) superior, necessitaram mais frequentemente de transfusões, terapêutica endoscópica e cirúrgica, e apresentaram taxas superiores de recidiva hemorrágica, mas com mortalidade semelhante. O score Completo-Rockall (CRS) e o GBS foram preditores de terapêutica endoscópica. A necessidade de cirurgia esteve associada ao CRS. Os doentes com recidiva hemorrágica tiverem superiores score Rockall pre-endoscópico (RS), CRS e GBS. Mortalidade superior esteve associada a RS e CRS mais elevados. Discussão/Conclusão: O envelhecimento e o aumento das comorbilidades não se associaram a piores outcomes na HDANH. Estes achados parecem ser consequência do uso adequado de ferramentas diagnósticas e terapêuticas num sistema de saúde organizado e amplamente acessível.

(c) 2021 Sociedade Portuguesa de Gastrenterologia Publicado por S. Karger AG, Basel

\section{Introduction}

Non-variceal upper gastrointestinal bleeding (NVUGIB) is a well-known healthcare problem with high mortality and morbidity. NVUGIB epidemiology and outcomes have been improving in the last years, side by side to medical and endoscopic advances. The most important factor to this progress was the change in the natural history of peptic ulcer disease (PUD), the most common cause of NVUGIB, due to the widespread use of proton pump inhibitors and eradication therapy of Helicobacter pylori. Other factors, related to the increased life expectancy, namely, the presence of several comorbidities and the use of drugs such as nonsteroidal anti-inflammatory drugs (NSAIDs), corticosteroids, selective serotonin reuptake inhibitors (SSRIs), antiplatelet agents, and oral anticoagulants, have also had an important role in NVUGIB evolution.

Several studies have shown a decreasing trend in worldwide NVUGIB incidence in the last two decades. Cavallaro et al. [1] found a clear decline in the incidence of upper gastrointestinal hemorrhage from 64.4 per 100,000 /year in 2001 to 35.9 per $100,000 /$ year in 2010 . Fonseca et al. [2] published in 2012 a retrospective study of 404 Portuguese patients with NVUGIB. The most frequent diagnosis was PUD (56\%); 5\% of patients had bleeding recurrence during hospitalization and overall mortality was $4.8 \%$.

The role of the timing of the endoscopy in patients' outcomes is also one of the most debated questions in NVUGIB outcomes. In Northern Portugal there is an out-of-hours Regional Gastroenterology Emergency covering a population of three million and ensuring a 24hour endoscopic assessment service, according do European guidelines [3].

The aim of our study was to characterize the current demographics, etiologies, and risk factors of NVUGIB in a tertiary Portuguese center [4]. We also pretended to evaluate prognostic factors of mortality, re-bleeding, admission in intermediate/intensive care unit (ICU), length of hospital stay, need for blood transfusion, endoscopic therapy, and surgery. A tertiary goal of this analysis was to identify differences in the outcomes between directly admitted patients versus transferred patients from other institutions.

\section{Materials and Methods}

We retrospectively reviewed data from patients admitted for NVUGIB between January 2016 and January 2019 in an emergency department of a tertiary hospital center in the north of Portugal with a gastroenterology team and endoscopy available $24 \mathrm{~h}$ a day, 7 days a week. From 8 p.m. to 8 a.m., there is an organized regional out-of-hours endoscopy model of care and patients can be directly admitted to this hospital's emergency service or be transferred from other institutions. Endoscopic registries of all urgent esophagogastroduodenoscopies (EGD) performed in this period were reviewed and medical and epidemiologic data was collected from electronic records of the patients with confirmed NVUGIB. Inclusion and exclusion criteria are presented in Figure 1.

The following characteristics were reviewed for each patient: sex, age, comorbidities and Charlson Comorbidity Index (CCI) [5], and use of proton pump inhibitors, SSRIs, NSAIDs, oral corticosteroids, antiplatelet and anticoagulant agents. Risk scores such as the Glasgow-Blatchford score (GBS), the pre-endoscopic 
Table 1. Demographic and clinical characteristics of patients presenting with non-variceal upper gastrointestinal bleeding

\begin{tabular}{|c|c|}
\hline Clinical characteristics & $n(\%)$ \\
\hline \multicolumn{2}{|l|}{ Age } \\
\hline$>65$ years & $316(60.5)$ \\
\hline \multicolumn{2}{|l|}{ Gender } \\
\hline Male & $384(73.6)$ \\
\hline Female & $138(26.4)$ \\
\hline \multicolumn{2}{|l|}{ Charlson Comorbidity Index } \\
\hline$\geq 6$ points & $172(33)$ \\
\hline$<6$ points & $313(60)$ \\
\hline \multicolumn{2}{|l|}{ Current medication at admission } \\
\hline PPIs & $95(18.2)$ \\
\hline NSAIDs & $68(13)$ \\
\hline SSRIs & $24(4.6)$ \\
\hline \multicolumn{2}{|l|}{ Antiplatelet agents } \\
\hline Mono antiplatelet therapy & $143(27.4)$ \\
\hline Aspirin & $120(23)$ \\
\hline Clopidogrel & $20(3.8)$ \\
\hline Dual antiplatelet therapy & $27(5.2)$ \\
\hline \multicolumn{2}{|l|}{ Anticoagulant agents } \\
\hline Warfin & $36(6.9)$ \\
\hline Acenocoumarol & $12(2.3)$ \\
\hline Enoxaparin/unfractionated heparin & $8(1.5)$ \\
\hline Oral corticotherapy & $7(1.3)$ \\
\hline \multicolumn{2}{|l|}{ Clinical presentation } \\
\hline Hematemesis & $181(34.7)$ \\
\hline Melena & $126(24.1)$ \\
\hline Hematemesis and melena & $65(12.5)$ \\
\hline Hematochezia & $15(2.9)$ \\
\hline Symptomatic anemia & $91(17.4)$ \\
\hline Others & $19(3.6)$ \\
\hline
\end{tabular}

PPIs, proton pump inhibitors; NSAIDs, nonsteroidal antiinflammatory drugs; SSRIs, selective serotonin reuptake inhibitors.

Rockall score (RS), and the complete Rockall score (CRS) were calculated as previously described [6,7]. Etiology of gastrointestinal bleeding and the timing of endoscopy were also recorded and categorized according to European Society of Gastrointestinal Endoscopy (ESGE) guidelines: very early $<12 \mathrm{~h}$, early $\leq 24 \mathrm{~h}$, and delayed $>24 \mathrm{~h}$ after admission to the index hospital [3].

Univariate analysis was performed to identify clinical factors predicting the following outcomes: need for blood transfusion, endoscopic therapy and surgery intervention, admission in ICU; duration of hospital stay, in-hospital rebleeding, and mortality rates. So, the following parameters were tested: age, gender, CCI $\geq 6$ vs. $<6$ points; use of NSAIDs, SSRIs, antiplatelet and anticoagulant drugs; clinical presentation and cause of NVUGIB.

Continuous variables were described by mean \pm SD. Differences in continuous variables were assessed using Student $t$ test for independent samples, after confirming homogeneity of variance with Levene's test. Categorical data were presented as absolute numbers and percent frequencies and the distributions were compared using chi-square test. A $p$ value $<0.05$ was considered statis-

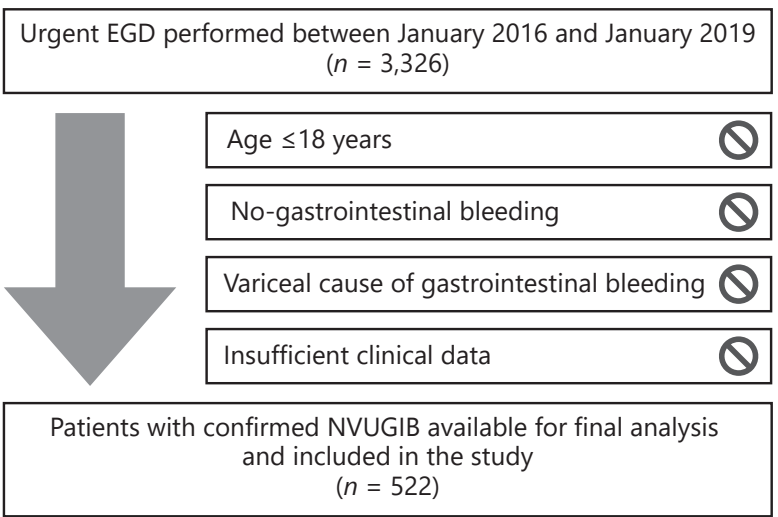

Fig. 1. Study population and exclusion criteria. EGD, esophagogastroduodenoscopies; NVUGIB, non-variceal upper gastrointestinal bleeding.

tically significant. SPSS (IBM SPSS Statistics for Windows, version 25.0. Armonk, NY, USA) was used for statistical calculations.

The study protocol was conducted in accordance with the standards of the Declaration of Helsinki. It was approved by the institutional Ethics Committee.

\section{Results}

\section{Baseline Patient Characteristics}

A total of 522 patients were included during the 37-month enrollment period. Patients were aged from 18 to 101 years, with a median age of 71 years (interquartile range $57-81$ ). $60.5 \%$ of the individuals were older than 65 years. The majority were men (73.6\%).

Congestive heart failure was the most frequent coexisting illness, present in $24.7 \%$ of the individuals, followed by diabetes mellitus (24.1\%), ischemic heart disease (13.8\%), and chronic liver disease (12.8\%). Among the subgroup of PUD patients, $16.3 \%$ had previous history of PUD. Mean (SD) CCI score was $4.7 \pm 3.1$.

The intake of NSAIDs, SSRIs, oral corticotherapy, and antiplatelet and/or anticoagulant drugs was mentioned in 278 individuals (53.3\%). NSAIDs use was significantly higher in PUD versus non-PUD patients (22.2 vs. 6.7\%, $p<0.001)$. The most frequent presenting complaint was hematemesis (47.1\%).

Most of the patients (68.8\%) were directly admitted to our institution, while the others were transferred from other hospitals. No significant differences were found between these two groups according to median age (71 vs. 73 years, $p=0.770$ ) or mean CCI (5.2 vs. $5.6, p=0.107$ ). 
Table 2. Endoscopic findings in NVUGIB patients

\begin{tabular}{lc}
\hline & $n(\%)$ \\
\hline Cause of NVUGIB & \\
Peptic ulcer disease & $251(48.1)$ \\
Gastric ulcer & $138(26.4)$ \\
Duodenal ulcer & $113(21.6)$ \\
Malignancy & $61(11.7)$ \\
Mallory-Weiss syndrome & $43(8.2)$ \\
Gastric angiodysplasia & $40(7.7)$ \\
Esophagitis & $23(4.4)$ \\
Dieulafoy lesion & $16(3.1)$ \\
Duodenal angiodysplasia & $10(1.9)$ \\
Hemorrhagic gastritis & $9(1.7)$ \\
Gastroduodenitis & $8(1.5)$ \\
GAVE & $8(1.5)$ \\
Esophageal ulcer & $7(1.3)$ \\
Others & $45(8.6)$ \\
Inconclusive & $1(0.2)$ \\
Stigmata of bleeding in peptic ulcer disease* & \\
Forrest Ia & $19(7.6)$ \\
Forrest Ib & $20(8)$ \\
Forrest IIa & $57(22.7)$ \\
Forrest IIb & $22(8.8)$ \\
Forrest IIc & $64(25.5)$ \\
Forrest III & $62(24.7)$ \\
\hline
\end{tabular}

NVUGIB, non-variceal upper gastrointestinal bleeding; GAVE, gastric antral vascular ectasia. ${ }^{*}$ According to Forrest classification.

Baseline demographic and clinical features of adult patients presenting with NVUGIB are exposed in Table 1.

\section{Endoscopic Features and Risk Stratification Scores}

A very early EGD was performed in 271 cases (51.9\%), an early EGD in 112 patients (21.5\%), and a delayed EGD in 65 cases $(12.5 \%)$. We found no statistically significant differences in the timing of EGD between directly admitted and transferred patients from other hospitals $(p=$ $0.539)$.

Our results show PUD as the most common cause of NVUGIB, representing $48.1 \%$ of all cases. In this subgroup, gastric ulcer was the most prevalent condition. The next most common diagnoses were upper gastrointestinal neoplasia (11.7\%), Mallory-Weiss syndrome $(8.2 \%)$, and gastric angiodysplasia (7.7\%). Other etiologies, individually, accounted for $<5 \%$. Additional endoscopic findings are presented in Table 2.

The global mean risk scores were 12. for GBS5, 3.4 for RS, and 5.3 for CRS. No significant differences in RS and CRS were found regarding the hospital of origin (RS 3.3 vs. 3.5, CRS 5.6 vs. 5.2 in transferred vs. directly admitted patients, respectively). However, a significantly higher GBS mean was seen for transferred patients (13.4 vs. 12.2, $p=0.004)$. Moreover, the minimum GBS score value registered for the transferred patients was 6 , whilst directly admitted patients presented scores of $\geq 0$.

\section{Clinical Outcomes}

Most of the patients (52.1\%) required blood transfusion before EGD. Transfusion needs were more frequently observed in older patients $(p=0.011)$, in patients with more comorbidities, represented by higher CCI values $(p=0.003)$, and in patients transferred from other institutions ( 65.2 vs. $50.8 \%, p=0.004)$. Any of the drug agents evaluated was related with need of blood transfusion. All scoring systems used were significantly superior in patients requiring blood transfusion: RS: $3.7 \pm 1.7$ vs. $3.0 \pm$ $1.0, p<0.001$; CRS: $5.7 \pm 2.0$ vs. $4.9 \pm 2.1, p<0.001$; GBS: $14.1 \pm 2.9$ vs. $10.6 \pm 3.6, p<0.001$.

Hemostatic endoscopic therapy was performed in 152 patients (29\%), most frequently in patients with confirmed PUD bleeding (34.3 vs. $24.4 \%, p=0.013$ ) and in transferred patients ( 41.5 vs. $23.7 \%, p<0.001)$. CRS was higher in patients who required endoscopic treatment $(6.0 \pm 1.8$ vs. $5.1 \pm 2.1, p<0.001)$ and so was GBS $(13.4 \pm$ 3.5 vs. $12.2 \pm 3.6, p=0.002)$. RS was not significantly related with the need for endoscopic therapy $(p=0.806)$.

Twenty-four patients (4.6\%) underwent surgery during the hospitalization and this need was significantly more common in patients presenting hematemesis $(9.0$ vs. $2.6 \%, p=0.004)$, with PUD bleeding versus other causes ( 9.8 vs. $1.8 \%, p<0.001$ ), and in transferred patients ( 13.3 vs. $3.7 \%, p=0.001)$. Surgery was needed in patients with higher CRS $(6.4 \pm 2.0$ vs. $5.2 \pm 2.0, p=0.010)$. This was not confirmed for RS or GBS.

The mean length of hospital stay was 8.8 days. This period increased with age: from 7.5 days in younger patients (18-44 years) to 9.1 days in patients older than 75 years. Hospitalization was also longer in patients who underwent a surgical procedure (17.1 days vs. 8.4 days, $p=$ $0.006)$. None of the risk scores were related to significant changes in duration of hospitalization.

ICU admission was decided in 186 patients (35.6\%) and was more frequent in patients presenting hematemesis (53.7 vs. $30.6 \%, p<0.001)$ and in patients with PUD bleeding versus other diagnosis ( 57.8 vs. $27.1 \%, p<0.001$ ). Transferred patients were also more frequently admitted to ICU (62.1 vs. $32.1 \%, p<0.001)$. Patients admitted to ICU had superior RS ( $3.6 \pm 1.8$ vs. $3.2 \pm 1.7, p=0.016)$, CRS (6.1 \pm 1.9 vs. $4.7 \pm 2.0, p<0.001)$, and GBS $(13.61 \pm$ 3.5 vs. $11.6 \pm 3.6, p<0.001)$. 
In-hospital rebleeding occurred in 36 patients (6.9\%) and was more frequent in cases of NVUGIB due to PUD than to other etiologies ( 11.6 vs. $5.2 \%, p=0.015)$ and in transferred patients ( 16.1 vs. $6.3 \%, p=0.003$ ). Mean GBS was superior in rebleeding versus non-rebleeding patients $(13.6 \pm 3.2$ vs. $12.3 \pm 3.6, p=0.039)$. This association was also valid for RS $(4.1 \pm 1.7$ vs. $3.3 \pm 1.4, p=0.006)$ and CRS ( $7 \pm 1.6$ vs. $5.1 \pm 2.1, p<0.001)$.

Overall, a total of 22 individuals (4.2\%) died after the index bleeding, during the period of hospitalization. Among these patients, 12 (54.5\%) died of bleeding-related causes. Previous comorbidities, namely CCI $\geq 6$, were associated with higher overall mortality $(p<0.001)$. The presence of hematemesis was also related to increased mortality rate ( 8.5 vs. $2.2 \%, p=0.003)$. No differences were found between transferred and directly admitted patients ( 4.9 vs. $5.2 \%$, respectively, $p=0.918$ ). Patients who died had superior RS ( $4.7 \pm 0.9$ vs. $3.3 \pm 1.7, p<$ $0.001)$. This was also confirmed for CRS (7.3 \pm 1.1 vs. 5.2 $\pm 2.0, p=0.001)$, although this was not confirmed for GBS $(12.7 \pm 5$ vs. $12.4 \pm 3.5, p=0.740)$.

\section{Discussion/Conclusion}

Upper gastrointestinal bleeding has changed its clinical and endoscopic characteristics over time, due to several factors that include the use of more effective medications and quality of endoscopic care. However, the impact of demographic factors and comorbidities have faded the improvement in these patients' outcomes.

Our study found an elderly population with multiple coexisting illnesses. European data from 1995 showed an upper gastrointestinal bleeding population with a mean age of 59.4 years and $30.9 \%$ of patients with no other health problems [8], versus $6.7 \%$ in our cohort $(\mathrm{CCI}<1)$. Recent European studies confirm this trend toward an older and frailer gastrointestinal bleeding population through the years $[1,2]$.

The main cause for NVUGIB remains PUD. However, the incidence of ulcer bleeding has reduced through time, mainly due to the parallel decrease in the incidence of the disease itself $[2,9]$. The significantly higher consumption of NSAIDs in PUD patients found in our cohort confirms NSAIDs as an important risk factor for NVUGIB. Several studies have shown a percentage of NSAIDs consumption around $40-49 \%$ in these patients $[8,10]$. The reduced NSAID intake referred in the present study might reflect a bias related to lost information and not a real decrease in the use of these drugs, which could be in- correctly assumed as an explanation for a less prevalent PUD bleeding.

The second most frequent cause of bleeding was neoplasia. The incidence of tumor bleeding has changed from $2.5 \%$ in 1995 to $8 \%$ in 2005 [8] versus $11.7 \%$ in our study. This evolution seems to be related with the aging of the population, but data is scarce. Sheibani et al. [11] showed that patients bleeding from tumors have worse outcomes, $75 \%$ needing blood transfusion and $50 \%$ with rebleeding recurrence.

Complying with the ESGE and other international recommendations $[3,12]$, the overwhelming majority of our patients underwent an EGD $\leq 24 \mathrm{~h}$ after hospital admission.

Around 52\% of our patients received blood transfusions. This value is lower compared to previous studies [2] and it is according to the current clinical evidence that supports a restrictive transfusion strategy in hemodynamically stable patients. One important limitation in the interpretation of our data is the lack of knowledge about the number of units of red blood cells transfused.

Need of endoscopic and surgery treatment was comparable to other studies $[1,2]$. Our overall mean length of hospitalization was the same than another European study, 8.8 days [1].

Rebleeding rates are not consistent between studies, varying from 4 to $10 \%[2,8,13]$, which embraces the $6.9 \%$ in-hospital rebleeding rate found in our population.

Trends in NVUGIB mortality vary between different groups of studies, but the majority has assumed stable rates in the last decades. Our mortality rate, $4.2 \%$, is inferior to the majority of previous studies $[2,8,12,14]$. These findings are related to overall mortality but it is important to enhance that only half of the deaths were bleeding-related. This should be a reminder for the importance of the support of other major organ systems. Concerning rebleeding and mortality, it is also important to highlight the definition of in-hospital rates, which could make a correct comparison to other studies with a larger period of follow-up difficult.

One of the distinguishing characteristics of the current study is to incorporate two groups of patients, transferred versus directly admitted. No differences were found regarding timing of endoscopy. GBS score, considered the best score identifying very low risk patients [15], was superior for transferred patients and we only registered transferred patients with GBS $\geq 6$ versus $\geq 0$ in directly admitted individuals. According to ESGE, patients with GBS score $\leq 1$ may be managed as outpatients, not requiring early endoscopy nor hospital admission. So, these re- 
sults showed a more careful use of endoscopic services in the transferred patients, especially in out-of-hours periods. On the other hand, we could reflect about a possible overuse of urgent endoscopic services in directly admitted patients. Regarding clinical outcomes, our study revealed higher rates of transfusion need, endoscopic therapy, surgery, ICU admission, and rebleeding in the transferred group. However, mortality rates were similar between the groups, which seems to express an efficient organizational structure.

The key strength of the present study is that it represents a comprehensive analysis of a large number of bleeding patients in a real-world clinical practice.

The findings of our data must be seen in light of some limitations. First, this was a single-center study, so results may not be generalized to other populations. Second, data was collected retrospectively from electronic medical records that were not standardized, leading to heterogeneity and potentially incomplete clinical reports, particularly in patients transferred from other hospitals.

In conclusion, our data showed that ageing and increasing comorbidities, including an increasing neoplasia-bleeding incidence, has not been translated into worse outcomes in NVUGIB patients.

These pleasant findings seem to be the consequence of the correct use of both diagnostic and therapeutic tools in association with an organized healthcare system.

\section{Statement of Ethics}

This study protocol was approved by the institute's committee on human research.

\section{Conflict of Interest Statement}

The authors have no conflicts of interest to declare.

\section{Funding Sources}

This study was not funded.

\section{Author Contributions}

The contribution of each author was the following: the concept and design of the article was thought by D.F. and I.P. Data collection was done by D.F. and J.A.d.S. Data analysis and interpretation were performed by D.F., J.A.d.S., T.P.G., M.G., and I.N. Drafting of the article was led by D.F. Critical revision of the article was performed by all the authors who approved the final version to be published.

\section{References}

1 Cavallaro LG, Monica F, Germanà B, Marin R, Sturniolo GC, Saia M. Time trends and outcome of gastrointestinal bleeding in the Veneto region: a retrospective population based study from 2001 to 2010. Dig Liver Dis. 2014 Apr;46(4):313-7.

2 Fonseca J, Alves CC, Neto R, Arroja B, Vidal $R$, Macedo G, et al. Nonvariceal upper gastrointestinal bleeding in Portugal: a multicentric retrospective study in twelve Portuguese hospitals. Gastroenterol Hepatol. 2012 JunJul;35(6):377-85.

3 Gralnek IM, Dumonceau JM, Kuipers EJ, Lanas A, Sanders DS, Kurien M, et al. Diagnosis and management of nonvariceal upper gastrointestinal hemorrhage: European Society of Gastrointestinal Endoscopy (ESGE) Guideline. Endoscopy. 2015 Oct;47(10): a1-46.

4 Pedroto I, Amaro P, Romãozinho JM. Health systems organization for emergency care. Best Pract Res Clin Gastroenterol. 2013 Oct;27(5):819-27.

5 Charlson ME, Pompei P, Ales KL, MacKenzie CR. A new method of classifying prognostic comorbidity in longitudinal studies: development and validation. J Chronic Dis. 1987;40(5):373-83.

6 Blatchford O, Murray WR, Blatchford M. A risk score to predict need for treatment for upper-gastrointestinal haemorrhage. Lancet. 2000 Oct;356(9238):1318-21.

7 Rockall TA, Logan RF, Devlin HB, Northfield TC. Risk assessment after acute upper gastrointestinal haemorrhage. Gut. 1996 Mar; 38(3):316-21.

8 Theocharis GJ, Thomopoulos KC, Sakellaropoulos G, Katsakoulis E, Nikolopoulou V. Changing trends in the epidemiology and clinical outcome of acute upper gastrointestinal bleeding in a defined geographical area in Greece. J Clin Gastroenterol. 2008 Feb; 42(2):128-33.

9 Lanas A, Dumonceau JM, Hunt RH, Fujishiro M, Scheiman JM, Gralnek IM, et al. Non-variceal upper gastrointestinal bleeding. Nat Rev Dis Primers. 2018 Apr;4(1):18020.

10 Loperfido S, Baldo V, Piovesana E, Bellina L, Rossi K, Groppo M, et al. Changing trends in acute upper-GI bleeding: a population-based study. Gastrointest Endosc. 2009 Aug;70(2):212-24.

11 Sheibani S, Kim JJ, Chen B, Park S, Saberi B, Keyashian K, et al. Natural history of acute upper GI bleeding due to tumours: shortterm success and long-term recurrence with or without endoscopic therapy. Aliment Pharmacol Ther. 2013 Jul;38(2):144-50.

12 Lau JY, Yu Y, Tang RS, Chan HC, Yip HC, Chan SM, et al. Timing of Endoscopy for Acute Upper Gastrointestinal Bleeding. N Engl J Med. 2020 Apr;382(14):1299-308.

13 Cho SH, Lee YS, Kim YJ, Sohn CH, Ahn S, Seo DW, et al. Outcomes and Role of Urgent Endoscopy in High-Risk Patients With Acute Nonvariceal Gastrointestinal Bleeding. Clin Gastroenterol Hepatol. 2018 Mar;16(3):3707.

14 Oakland K. Changing epidemiology and etiology of upper and lower gastrointestinal bleeding. Best Pract Res Clin Gastroenterol. 2019 Oct-Dec;42-43:101610

15 Stanley AJ, Laine L. Management of acute upper gastrointestinal bleeding. BMJ. 2019 Mar;364:1536. 